Psychopharmacologia 5, 289-300 (1964)

Department of Pharmacology, University of Michigan, Ann Arbor

\title{
Some Effects of Muscarinic Cholinergic Blocking Drugs on Behavior and the Electrocorticogram*
}

By

\author{
Barton Meyers **, Kelyn H. Roberts***, Remo H. Riciputi* \\ and Edward F. Domino
}

With 4 Figures in the Text

(Received September 23, 1963)

A persisting enigma is the fact that cholinergic blocking drugs cause a "dissociation" between electroencephalographic (EEG) activity and gross behavior (BRADLeeY and EuKes 1957; WIKLER 1952). Although these drugs produce EEG's typical of somnolence or coma, gross behavior is apparently unaltered. This finding has led to attempts to determine more precisely defined behaviors which are affected by cholinergic blocking drugs.

One of the most intriguing findings is that these agents markedly impair the acquisition, but not the retention, of learned behaviors (Herz 1960; Micherson 1961). Herz suggested that this dichotomous effect results from a disturbance of recent memory. Indeed, adequate doses of atropine (MigDaL and Frumin 1963; OstrektD et al. 1960) and scopolamine (GoodMAN and GILMAN 1955) cause recent memory loss in man.

The fact that cholinergic blocking drugs may cause a recent memory loss prompted us to replicate the findings of HERz using scopolamine and the more active isomer of atropine, 1-hyoscyamine. In addition, the effects of these agents on spontaneous electrocortical activity and on spontaneous psychomotor activity were studied in an effort to clarify some of the relevant variables. For purposes of clarity the data will be presented as four separate experimental section.

\section{Experiment I}

The effects of cholinergic blocking drugs on the acquisition of a conditioned avoidance response

Methods. Eighty-four male rats (Holtzmann), ranging from 48 to 62 days of age, served as the subjects. They were randomly assigned, with the restriction of equal numbers, to 7 groups receiving 0.13 or

* This work was supported in part by USPHS Grant MY -02653.

** United States Public Health Service Postdoctoral Fellow MPD-12, 702-C2. Present address: Department of Psychology, Brooklyn College, Brooklyn 10, N.Y.

**** Present address: Department of Psychology, University of Michigan.

* Present address: Department of Fisheries, University of Michigan. 
$1.05 \mathrm{mg} / \mathrm{kg}$ scopolamine hydrobromide, 1.0 or $8.0 \mathrm{mg} / \mathrm{kg}$ 1-hyoscyamine hydrobromide, 2.1 or $16.8 \mathrm{mg} / \mathrm{kg}$ methyl atropine nitrate ${ }^{1}$, or physiological saline. All doses were as base and were given subcutaneously. On the basis of data in the literature, it was assumed that scopolamine is approximately eight times as potent as 1-hyoscyamine. Calculating on a molar basis, therefore, the $\mathrm{mg} / \mathrm{kg}$ ratio of scopolamine to 1-hyoscyamine chosen was one-eighth. Methyl atropine doses were twice that of 1-hyoscyamine. All injections were of equal volume.

Twenty-five minutes after injection, the animals were placed in the experimental compartment, which housed a modified pole-jump apparatus

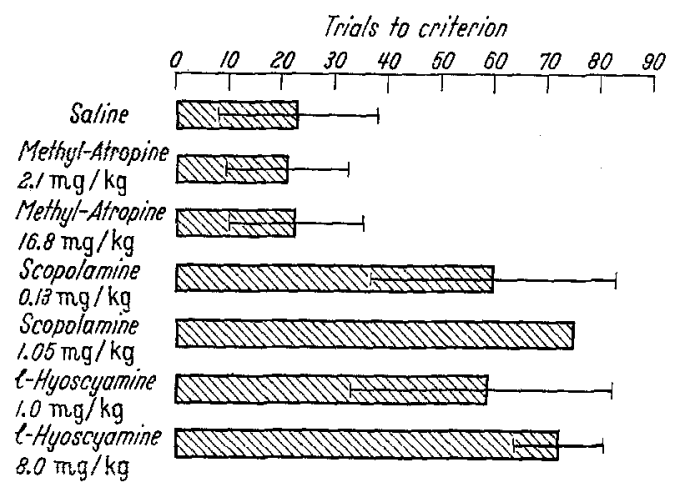

Fig. 1. Effects of various cholinergic blocking drugs on acquisition of a pole-jump response. Means and standard errors for trials to criterion are presented for each agent
(COOK and WEIDLEY 1957). The compartment was $45 \mathrm{~cm}$ by $45 \mathrm{~cm}$ and had a grid floor. After 5 min of exposure, the rats were trained on a conditioned avoidance schedule. The conditioned stimulus (CS), a buzzer, was presented for 5 sec and then overlapped for 5 see with the unconditioned stimulus (US), a 1.0 ma. "scrambled" shock ad-

ministered through the grid floor. Both CS and US intervals were controlled by automatic timers. An avoidance response of jumping onto the pole during the CS interval activated a microswitch which terminated the buzzer and prevented the onset of the US. An escape response during the US interval terminated both the CS and US. Intertrial intervals ranged from $20 \mathrm{sec}$. to $2 \mathrm{~min}$ with an average of $1 \mathrm{~min}$. The criterion for acquisition was 9 avoidance responses within 10 consecutive trials. Failure to achieve criterion within 75 trials was arbitrarily designated as the terminal point of training. The pole-jump apparatus was enclosed in a sound-reducing box with a one-way mirror, which permitted observation of the animals.

Results. The various groups differed significantly $(p<.001$; KruskalWallis one-way analysis of variance; SIEGEL 1956) on the measure of trials to criterion (Fig. 1). Although the methyl atropine groups achieved criterion as rapidly as the saline group ( $p>.05$; one-tailed MannWhitney U test; STEGEL 1956), significant retardation in acquisition was

1 The methyl atropine was kindly supplied by Dr. C. PEErfFer (New Jersey Psychiatric Institute, Princeton, N.J.). 
observed with the low $(0.13 \mathrm{mg} / \mathrm{kg}$ scopolamine and $1.0 \mathrm{mg} / \mathrm{kg} 1$.hyoscyamine; $p<.01)$ and high doses $(1.05 \mathrm{mg} / \mathrm{kg}$ scopolamine and $8.0 \mathrm{mg} / \mathrm{kg}$ 1-hyoscyamine; $p<.001$ ) of the drugs with potent central actions. In fact, only one animal receiving $8.0 \mathrm{mg} / \mathrm{kg}$ l-hyoscyamine and none of those receiving $1.05 \mathrm{mg} / \mathrm{kg}$ scopolamine achieved criterion. Among the scopolamine and 1-hyoscyamine groups, only the difference in performance between the $0.13 \mathrm{mg} / \mathrm{kg}$ and $1.05 \mathrm{mg} / \mathrm{kg}$ scopolamine groups approached significance $(p=.05)$. The failure to find clear differences on the number of trials to criterion among these groups almost certainly resulted from the restriction of such differences imposed by the arbitrary terminal point of training: at 75 trials.

Reference to the percentage of avoidance responses made during acquisition (Fig. 2) is also revealing. Again, the groups differed $(p<.001)$. In addition to the performance disparities mentioned above (which were again evident by this measure), the behavior of the low dose groups was different from that Percentage avoidance responses

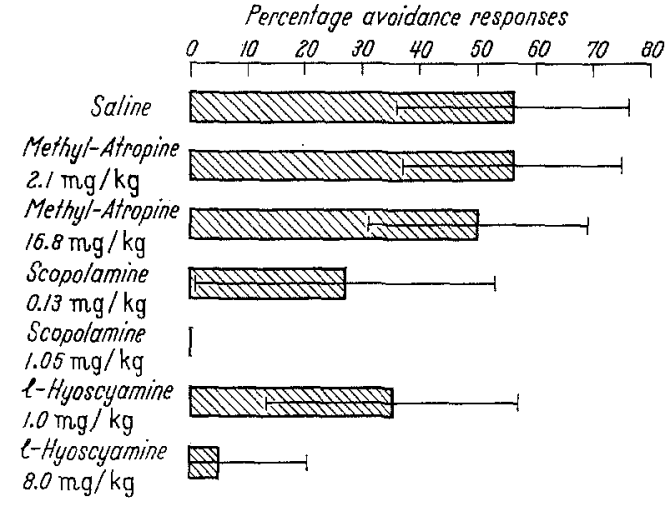

Fig. 2. Effects of various cholinergic blocking drugs on the percentage of avoidance responses. Means and standard errors are presented for each agent of the high dose groups

for both 1-hyoscyamine and scopolamine. The $0.13 \mathrm{mg} / \mathrm{kg}$ scopolamine animals avoided more often than the $1.05 \mathrm{mg} / \mathrm{kg}$ scopolamine animals $(p<.025)$, as did the $1.0 \mathrm{mg} / \mathrm{kg} 1$-hyoscyamine animals compared to the $8.0 \mathrm{mg} / \mathrm{kg} 1$-hyoscyamine animals $(p<.001)$. The performance of the low dose scopolamine and 1-hyoscyamine groups was indistinguishable, as was the performance of the two high dose groups $(p>.05)$. The data on average response latencies demonstrated the same differences found with percentage avoidance and therefore is not presented.

These dose-response effects on percentage avoidance reflected two facts. First, only two of the $8.0 \mathrm{mg} / \mathrm{kg} \mathrm{l}$-hyoscyamine animals and none of the $1.05 \mathrm{mg} / \mathrm{kg}$ scopolamine animals emitted any avoidance responses. Secondly, many animals in both the $0.13 \mathrm{mg} / \mathrm{kg}$ scopolamine and $1.0 \mathrm{mg} / \mathrm{kg}$ 1-hyoscyamine groups often vacillated back and forth between emitting a series of avoidance responses and emitting either escape responses or no responses at all. This behavior was rarely seen in control animals. Thus, the animals in these two groups required many trials to achieve criterion but, in the process, often made avoidance responses. 


\section{Experiment II}

\section{The effects of eholinergie blocking drugs on the retention of a conditioned avoidance response}

Methods. Seventy-two male rats (Holtzmann), ranging in age from 48 to 59 days at the start of the experiment, served as subjects. They were randomly assigned in equal numbers to 6 groups, 4 of which received scopolamine hydrobromide or 1-hyoseyamine hydrobromide in the same doses used in Experiment I. One control group again received physiological saline while the last group was injected with $1.10 \mathrm{mg} / \mathrm{kg}$ $\mathrm{N}$-methyl scopolamine bromide (Pamine) $)^{1}$ as base. All animals were trained, again on the pole-jump avoidance response, for 4 consecutive days. Training on the first day was identical to that in the acquisition study except that no drugs were administered. On the second and third days, the animals were retrained to the original criterion. On the fourth day, the animals were injected. with the various drugs and then, after $1 / 2 \mathrm{hr}$., given 20 retention trials with shock reinforcement.

Results. As an index that training was the same for all groups, performance on the first three days of training was averaged and compared. The various groups did not differ $(p>.05)$ on the measures of trials to criterion, percentage avoidance, or average response latencies. Performance on the fourth, or retention, day was evaluated by the measures of percentage avoidance and average response latencies. Minor, but nevertheless significant, differences were found among the groups on percentage avoidance (Table 1 ). The saline animals made more

Table 1. Effects of various cholinergic blocking agents on the retention of the pole jump response. On days $1-2$ the percentage avoidance responses to achieve criterion are listed. The drugs were given on day 4

\begin{tabular}{|c|c|c|c|c|}
\hline \multirow{3}{*}{ Drug } & \multicolumn{4}{|c|}{ Mean percentage \pm S. E. of avoidance responses } \\
\hline & \multicolumn{4}{|c|}{ Days } \\
\hline & 1 & 2 & 3 & 4 (test) \\
\hline $\begin{array}{l}\text { Saline . . . . . } \\
0.13 \text { Scopolamine } 1 . \\
\text { 1.05 Scopolamine . } \\
\text { 1.1 Methyl scopolamine } \\
\text { 1.0 1-Hyoscyamine . . } \\
8.0 \text { 1-Hyoseyamine . . }\end{array}$ & $\begin{array}{l}59(16) \\
46(20) \\
56(18) \\
51(18) \\
54(17) \\
55(18)\end{array}$ & $\begin{array}{l}86(20) \\
92(9) \\
91 \quad(8) \\
93 \quad(9) \\
86(16) \\
88(10)\end{array}$ & $\begin{array}{r}91(9) \\
97(4) \\
98(3) \\
93(9) \\
100(0) \\
96(6)\end{array}$ & $\begin{array}{ll}98 & (3) \\
93 & (7) \\
82 & (25) \\
97 & (4) \\
89 & (8) \\
98 & (3)\end{array}$ \\
\hline
\end{tabular}

avoidance responses than the $1.05 \mathrm{mg} / \mathrm{kg}$ scopolamine animals $(p<.01)$ and than the $1.0 \mathrm{mg} / \mathrm{kg}$ 1-hyoscyamine animals $(p<.05)$. Similarly, the $8.0 \mathrm{mg} / \mathrm{kg} 1$-hyoscyamine animals avoided more often than the

1 The Pamine was generously supplied by Dr. WEBB (Upjohn Co., Kalamazoo, Michigan). 
$1.05 \mathrm{mg} / \mathrm{kg}$ scopolamine $(p<.01)$ and the $1.0 \mathrm{mg} / \mathrm{kg}$ 1-hyoscyamine $(p<.025)$ animals.

Conversely, there were no significant differences among groups on the measure of average response latencies on the retention test (Table 2). It would appear that this measure, rather than percentage avoidance, is the more meaningful one. This is because the latency measure takes account of more of the data. That is, an escape response with a short latency, indicating some degree of retention, is lost with the measure of percentage avoidance, but not with that of average response latencies. Thus retention of a conditioned avoidance response is essentially unimpaired by cholinergic blocking drugs in the doses used here.

Table 2. Effects of various cholinergic blocking agents on the retention of the pole jump response. On days 1 -3 the mean latency of responses to achieve criterion is listed. The drugs were given on day 4

\begin{tabular}{l|c|c|c|c}
\hline \multirow{2}{*}{ Drug } & \multicolumn{4}{|c}{ Mean response latency (in sec) \pm S.E. } \\
\cline { 2 - 5 } & \multicolumn{4}{|c|}{ Days } \\
\cline { 2 - 5 } & 1 & 2 & 3 & 4 (test) \\
\hline Saline . . . . . . & $5.14(1.31)$ & $2.58(1.72)$ & $1.96(0.59)$ & $1.75(0.49)$ \\
0.13 Scopolamine ${ }^{1}$. & $5.96(1.81)$ & $2.27(0.66)$ & $1.85(0.53)$ & $1.98(0.67)$ \\
1.05 Scopolamine . . & $5.34(1.39)$ & $2.15(0.61)$ & $1.83(0.59)$ & $2.96(2.16)$ \\
1.1 Methyl scopolamine & $5.50(1.38)$ & $2.11(0.71)$ & $2.07(0.73)$ & $1.92(0.75)$ \\
1.0 1-Hyoscyamine . . & $5.45(1.49)$ & $2.52(1.38)$ & $1.40(0.31)$ & $1.89(0.81)$ \\
8.0 1-Hyoscyamine . . & $5.32(1.32)$ & $2.53(0.80)$ & $1.59(0.60)$ & $1.90(0.40)$ \\
1 Doses in mg $/ \mathrm{kg}$ S.C. & & & & \\
\end{tabular}

Experiment III

The effects of cholinergic blocking drugs on spontaneous activity

Methods. Forty-nine male rats (Holtzmann), ranging from 54 to 57 days of age when the experiment began, served as subjects. They were randomly divided, with the restriction of equal numbers, into 7 groups. On the first and third days of this experiment, all animals received injections of physiological saline. On the second day, however, they were injected with either scopolamine, 1-hyoscyamine, or methyl atropine. The doses and route of administration were the same as in Experiment I, except that a $2.1 \mathrm{mg} / \mathrm{kg}$ scopolamine group was added. One half hour after injection on each of the three days, the animals were placed in activity cages for a $1 / 2$ hour period. The cages ${ }^{1}$ were those described by BASTIAN and HILL (1957). They were made of perforated aluminum and measured $17.5 \mathrm{~cm}$ by $11.5 \mathrm{~cm}$ by $5 \mathrm{~cm}$. The eage bottom was balanced on an edge along its short dimension, and the cage was attached to the armature of a mechanical counter. Thus, movements of the rat back and forth along the length of the cage were registered on the counter and an indication of activity obtained.

\footnotetext{
${ }^{1}$ Motor-meter (A and B Products, 463 Titonka Street, Park Forest, Ill.).
} 
Results. The findings were analyzed by comparing the activity, as registered on the counter, on the day the drugs were administered to the mean activity of the two days when saline was administered (Fig. 3). Most of the drugs produced significant changes in the level of activity. All doses of scopolamine used and $1.0 \mathrm{mg} / \mathrm{kg}$ 1-hyoseyamine increased spontaneous activity ( $p=.02$; two-tailed Wilcoxin sign-rank test of differences; SIEGEL 1956). Conversely, activity was reduced after the

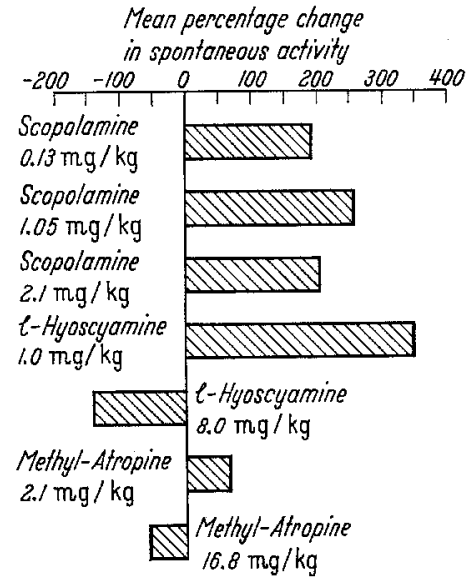

Fig. 3. Percentage change of spontaneous motoric activity with various cholinergic blocking drugs. The baseline represents the mean activity obtained with saline injection of $8.0 \mathrm{mg} / \mathrm{kg}$ 1-hyoscyamine $(p=.02)$ or of $16.8 \mathrm{mg} / \mathrm{kg}$ methyl atropine $(p=.05)$. Only $2.1 \mathrm{mg} / \mathrm{kg}$ methyl atropine failed to have a significant effect $(p>.05)$.

Comparisons (two-tailed MannWhitney-U-tests) of the activity levels characteristic of the various drug groups revealed that the three scopolamine groups and the $1.0 \mathrm{mg} / \mathrm{kg}$ 1-hyoscyamine group did not differ among themselves $(p>.62)$, but did differ from the two methyl atropine groups and the $8.0 \mathrm{mg} / \mathrm{kg} 1$-hyoscyamine group $(p<.05)$. In turn, these latter groups did not differ among themselves $(p>.07)$.

\section{Experiment IV}

The effects of cholinergic blocking drugs on spontaneous electrocortical activity

Methods. Thirteen mature, male rats (Holtzmann), ranging in weight from 230 to $430 \mathrm{gm}$, were used. The animals were anesthetized with diethyl ether and the trachea exposed surgically and cannulated for artificial respiration. The animals were then given 2 to $3 \mathrm{mg} / \mathrm{kg} \mathrm{d}$-tubocurarine intraperitoneally, placed on artificial respiration, and the diethyl ether anesthesia discontinued. All wound edges were infiltrated with $1 \%$ xylocaine. Electrocorticograms (ECG) were recorded monopolarly from bilateral, somatosensory cortical areas through the use of small phonograph needles. After infiltration with xylocaine, the scalp was incised at the midline and retracted. The electrodes were gently pounded into the calvarium to barely make contact with the dura. At least $1 \mathrm{hr}$. was allowed to intervene between the end of ether anesthesia and the beginning of the experiments. 
After injecting physiological saline and obtaining control records, the effects of scopolamine, 1-hyoseyamine, and methyl atropine on the ECG were determined. The doses of the drugs were the same as those used in Experiment I. Typically, animals received more than one dose of a drug (with at least $1 \mathrm{hr}$. interposed between injections), but no animal was ever given more than one drug. At least three experiments were performed with each dose. All injections were given subcutaneously. The recordings were taken with either an Offner Type $R$ Dynograph or on a Grass Model III C electroencephalograph.
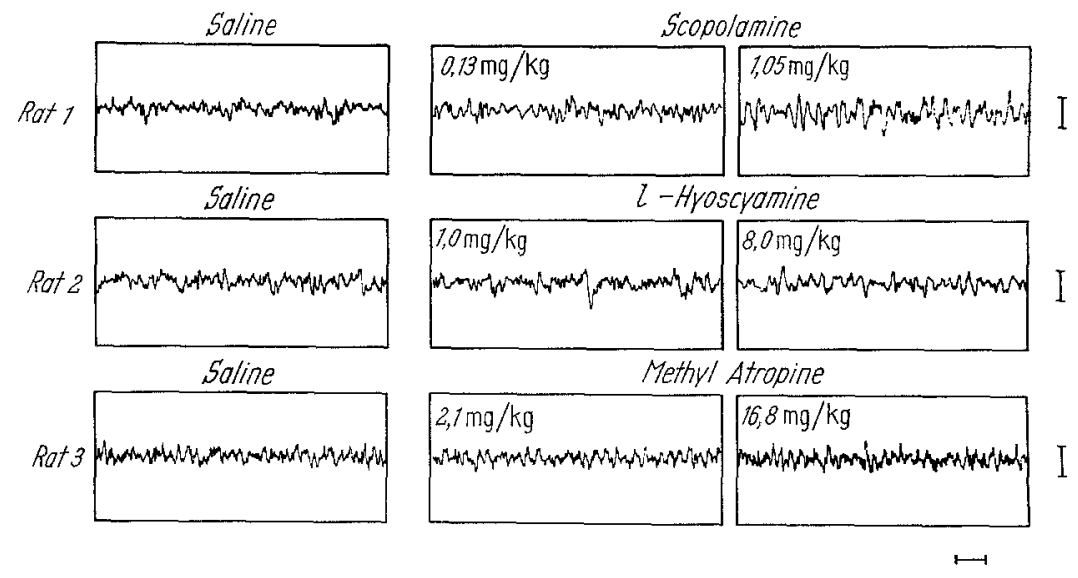

Fig. 4. Effects of various cholinergic blacking agents on the ECG of the rat. Monopolar recordings of the ECG of the right somatosensory area to the nose as the reference are shown. All recordings were taken one half hour after subcutaneous injection. The height of the vertical bars indicate 200 microvolts and the length of the horizontal bar 1 sec

Results. Compared to the recordings obtained with saline, all of the drugs in the doses used had some effect on the ECG (Fig. 4). In all cases, this effect was in the direction of higher amplitude and slower frequency. Often there appeared to be an increased synchrony of the waves. These phenomena were dose related and also seemed to vary with the particular drug. Thus, the lower of the two doses of each drug did not have a very dramatic effect while the higher dose usually produced a marked change. Scopolamine was more effective than methyl atropine. These ECG changes were always present at $30 \mathrm{~min}$ postinjection and persisted for at least another 20 to $25 \mathrm{~min}$.

\section{Discussion}

The major finding of this study is that muscarinic cholinergic blocking drugs specifically 1-hyoscyamine and scopolamine, markedly disrupt the acquisition, but not the retention, of a conditioned avoidance response. The ineffectiveness of methyl atropine and methyl scopol- 
amine, which have cholinergic blocking actions primarily at peripheral sites, for altering the behaviors studied indicates that the action is on the central nervous system. Thus the results confirm previous findings (HeRz 1960; Michelson (1961).

Although some effect of scopolamine and 1-hyoscyamine on retention was observed, it is felt that retention was essentially unimpaired (see Results, Experiment II). Had the animals been given more training prior to being tested for retention, it is probable that no disruption whatsoever would have occurred. Indeed, HERz, who trained his animals 8 to 12 days before testing for retention, not only found no impairment with scopolamine, but even a suggestion of enhanced performance. It would appear, therefore, that cholinergic blocking drugs fail to degrade conditioned avoidance behavior to the extent to which it is overtrained or consolidated.

The present findings on spontaneous activity indicate that the poor performance during acquisition by some of the groups was not due to a gross motoric depression. In fact, among the experimental groups only $8.0 \mathrm{mg} / \mathrm{kg}$ 1-hyoscyamine reduced activity significantly, while increased activity was noted for the other groups. Moreover, a significant decrease in activity was observed for the $16.8 \mathrm{mg} / \mathrm{kg}$ methyl atropine group, yet their acquisition of the conditioned avoidance response was unimpaired. Furthermore, it does not seem likely that changes in activity would disrupt acquisition while failing to affect retention.

Additionally, the data on spontaneous activity have intrinsic interest. Although cholinergic blocking drugs, especially scopolamine, have a sedative effect on humans (Goodmar and GILMAN 1955; OSTFELD et al. 1960), they appear to act in rats as psychomotor stimulants in at least some of the doses used. The relatively slight effect of methyl atropine in altering activity implies a central nervous system site of action of 1-hyoscyamine and scopolamine. This finding validates similar incidental observations on the effect of scopolamine in rabbits (SADOWSKI and LoNGo 1962). The data also suggest an inverted U type of effect, i.e., the existence of an optimal dose for increasing spontaneous activity with larger doses either having a lesser effect or even depressing activity. Such a relationship can be inferred from data previously reported (MACHT 1924).

The ECG results imply confirmation of previous observations of the "dissociation" of ECG and behavior (WIKLER 1952; BRADLEY and ELkEs 1957). In doses which produced ECG patterns typical of somnolence or coma, rats did not necessarily display a depression of gross or learned behavior. For example, although $1.0 \mathrm{mg} / \mathrm{kg}$ scopolamine produced increased psychomotor activity while $8.0 \mathrm{mg} / \mathrm{kg}$ I-hyoscyamine 
produced a decrease of such activity, both agents created similar high voltage, slow activity in the ECG. In fact, this dose of scopolamine appeared to have an even more potent effect than 1-hyoscyamine in producing such ECG activity. Although $16.8 \mathrm{mg} / \mathrm{kg}$ of methyl atropine caused marked slowing of the ECG, it failed to alter conditioned avoidance. Furthermore, all of the doses of scopolamine and 1-hyoscyamine used had a dramatic effect on the acquisition, but not on the retention, of a conditioned avoidance response. Yet, it can be presumed that the effects of these drugs on the cortical activity of the animals was the same regardless of whether they were initially acquiring or demonstrating retention of this learned response.

Thus, it can be concluded that the ECG as affected by cholinergic blocking drugs is not helpful in analyzing the mechanisms involved in regulating this type of behavior. There is, in fact, a "dissociation" between the ECG and behavior. It is not clear at this time, however, whether the ECG, as recorded with macroelectrodes, is too gross a technique to have relevance for pharmacologically manipulated behavior or if cortical structures are relatively unimportant for the behavior studied. Perhaps the critical site of action of cholinergic blocking drugs is subcortical rather than cortical.

The hypothesis of CARLTON (1963), concerning the function of cholinergic systems, does not appear adequate for explaining the results of the conditioned avoidance experiments. He suggests that central cholinergic systems are inhibitory and are in a reciprocal balance with adrenergic systems which are excitatory. Since cholinergic systems are posited to normally inhibit unreinforced responses, the administration of cholinergic blocking drugs should result in their release. This explanation might fit the acquisition data since retarded learning can be conceived of as the continued emission of unreinforced responses. However, it would appear that this hypothesis cannot explain the failure of these drugs to disrupt retention as well.

A more probable explanation is that cholinergic blocking drugs impair recent memory. As mentioned above, these drugs do have amnesic properties in humans (Goodman and GILMan 1955; MigDaL and Frumin 1963; OSTFELD et al. 1960). The dichotomous effect of these agents on acquisition and retention of a learned response can also be conceived of as involving recent memory. During acquisition the animal must remember from one trial to the next which responses were appropriate and which inappropriate. Conversely, during retention the animal can be presumed to have available a well-consolidated memory trace, acquired in the past and independent of recent memory. Finally, the behavior of vacillating back and forth between making avoidance responses and 
making no such responses, which was characteristic of the low dose scopolamine and 1-hyoscyamine animals during acquisition, is highly suggestive of a recent memory deficit. It appeared as if they would discover the correct response, forget it, rediscover it, and so forth.

Hypotheses concerning a possible site of action of these drugs must, at this time, be highly speculative. It can be stated that the site is in the central nervous system since methyl atropine, although having some central effects (PAUL-David et al. 1960; also Results, Experiment IV), was relatively ineffective in altering the behaviors studied. Within the central nervous system, cholinergic blocking drugs probably have widespread effects. If it is correct that muscarinic cholinergic systems are implicated in the process of recent memory, however, it may be that a critical site of action is in medial temporal structures. These structures, and particularly the hippocampus, appear to be intimately associated with the process of recent memory (ScovmLE and MrLNER 1957; Walker 1957; Penfield and Milner 1958; Stepien et al. 1960; Fuexwor et al. 1963). Also, rats with hippocampal lesions display increased spontaneous activity (Teimelbaum and MrLner 1963), as did rats treated with most of the doses of cholinergic blocking drugs in the present study. Moreover, the findings demonstrating a high concentration of endogenous acetylcholine in the hippocampus (FELDBERG and Vogt 1948; Gerebtzoff 1959; HeBB and Silver 1956) indicate the a vailability of this structure as a site of action. Thus it is suggested that the possibility be investigated that the hippocampus is an important component of a muscarinic cholinergic system.

\section{Summary}

Results are presented for the effects of drugs with muscarinic cholinergic blocking actions, both central and peripheral (scopolamine and 1-hyoscyamine) and primarily peripheral (methyl atropine and methyl scopolamine), on conditioned avoidance behavior, spontaneous motor activity, and the ECG in the rat.

Low doses of the agents with central actions retarded acquisition of conditioned avoidance, while high doses virtually abolished it. Both low and high doses were essentially ineffective in altering retention of conditioned avoidance. Agents with primarily peripheral actions had no effect on acquisition or retention.

Most of the agents produced an increase in spontaneous activity although there was a definite suggestion that higher doses depress activity. 
All of the agents used provoked a high amplitude, slow frequency ECG. This phenomenon was dose-related; scopolamine appeared to be most effective.

It is suggested that the disruption of the acquisition, but not retention, of conditioned avoidance is due to a deficit of recent memory. A possible site of action of cholinergic blocking drugs is proposed.

\section{References}

Bastian, J. W., and R. G. Hill: A simplified method for measuring motor activity in mice. J. Pharmacol. exp. Ther. 119, 132 (1957).

Bradley, P. B., and J. ElkEs: The effect of some drugs on the electrical activity of the brain. Brain 80, 77-117 (1957).

CARlton, P. L.: Cholinergic mechanisms in the control of behavior by the brain. Psychol. Rev. 70, 19-39 (1963).

Cook, L., and E. WEIDLEY: Behavioral effects of some psychopharmacological agents. Ann. N.Y. Acad. Sci. 66, 740-752 (1957).

Feldobrg, W., and M. Vogt: Acetylcholine synthesis in different regions of the central nervous system. J. Physiol. (Lond.) 107, 372-381 (1948).

Flexner, J. B., L. B. Flexner and E. Stellar: Memory in mice as affected by intracerebral puromycin. Science 141, $57-59$ (1963).

Gerebtzoff, M. A.: Cholinesterases: a histochemical contribution to the solution of some functional problems. New York: Pergamon Press 1959.

Goodman, L. S., and A. Gtrman: The pharmacological basis of therapeutics, 2nd edit. New York: Macmillan 1955.

HEBB, C. O., and A. StLver: Choline acetylase in the central nervous system of man and some other mammals. J. Physiol. (Lond.) 134, 718-728 (1956).

HERz, A.: Die Bedeutung der Bahnung für die Wirkung von Scopolamin and ähnlichen Substanzen auf bedingte Reaktionen. Z. Biol. 112, 104-l12 (1960).

MACHT, D. I. A.: A pharmacodynamic analysis of the cerebral effects of atropin, homatropin, scopolamin und related drugs. J. Pharmacol. exp. Ther. 22, 35-48 (1924).

Mrohelson, M. J.: Pharmacological evidences of the role of acetylcholine in the higher nervous activity of man and animals. Activ. nerv. sup. (Praha) 3, $140-147$ (1961).

Mrgdal, W., and M. J. Frumir: Amnesic and analgesic effects in man of centrally acting anticholinergics. Fed. Proc. 22, 188 (1963).

OstFend, A. M., X. MACHNe and K. R. UnNa: The effects of atropine on the electroencephalogram in man. J. Pharmacol. exp. Ther. 128, 265-272 (1960).

PAUL-DAVID, J., J.-L. RIEHL and K. R. UNNA: Quantification of effects of depressant drugs on EEG activation response. J. Pharmacol. exp. Ther. 129, $69-74(1960)$.

Penfield, W, and B. Minner: Memory deficit produced by bilateral lesions in the hippocampal zone. Arch. Neurol. Psychiat. (Chic.) 79, 475-497 (1958).

SADOWSKI, B., and V.G. LoNGO: Electroencephalographic and behavioral correlates of an instrumental reward conditioned response in rabbits. Electroenceph. clin. Neurophysiol. 14, 465-476 (1962).

Scoville, W. B., and B. MILNER: Loss of recent memory after bilateral hippocampal lesions. J. Neurol. Neurosurg. Psychiat. 20, 11-21 (1957). 
SLEGEL, S.: Nonparametric statistics. New York: McGraw-Hill Book Co. 1956.

Stepien, L. S., J. P. Cordeau and T. Rasmussen: The effect of temporal lobe and hippocampal lesions on auditory and visual recent memory in monkeys. Brain 83, 470-489 (1960).

Teitelbaum, H., and P. Mulner: Aotivity changes following partial hippocampal lesions in rats. J. comp. physiol. Psychol. 56, 284-289 (1963).

WALKER, A. E.: Recent memory impairement in unilateral temporal lesions. Arch. Neurol. Psychiat. (Chic.) 78, 543-552 (1957).

WIKLER, A.: Pharmacologic dissociation of behavior and EEG "sleep patterns" in dogs: morphine, N-allylnormorphine, and atropine. Proc. Soc. exp. Biol. (N.Y.) 79, 261-265 (1952).

Edward F. Domrno, M. D. Professor of Pharmacology, The University of Michigan M 6322 Medial Science Building, Ann Arbor, Michigan, USA 